\section{Seaside story}

\section{J. H. Steele}

Biological Oceanography: An Early History 1870-1960. By Eric L. Mills. Cornell University Press: 1989. Pp. 378. $\$ 47.95$. Distributed in the United Kingdom by Trevor Brown, £26.

I ENJOYED reading this book. It is clearly written and is based on thorough research so that a great deal of historical information is conveyed effectively. But oceanographers, like most other scientists, are not particularly interested in the history of science, even if it concerns their own field. Are there other reasons, apart from curiosity, for reading this book? I think there are.

First, the subject matter. The history of biological oceanography is restricted here to developments in the study of plankton dynamics. The author regards basic productivity as the core of this field, but even within this category the work of some well-known oceanographers, such as Marshall and Orr, Steeman Nielsen and John Ryther, are mentioned only briefly or not at all. However, this allows Mills to focus on his main theme, the rise and fall of centres of excellence, especially those at Kiel University from 1890 to 1920 , and the Marine Biological Laboratory in Plymouth from 1925 to 1940 . Both of these centres had intellectual leaders - Hensen and Brandt in Germany and Harvey in England - and each group involved several other active researchers. (It is relevant to note that none of these people had graduate training in his final field of research: Victor Hensen's initial research, in about 1860 , was on glycogen and epilepsy; and W. H. Harvey took a degree in chemistry and worked in the family paint business before going to Plymouth in 1921.)

Some members of these groups are remembered for their individual contributions but others are not. Among the latter group, I was fascinated to read about Alexander Nathanson who, between 1906 and 1910, defined the significance of vertical mixing between the upper layers of the ocean in the control of plankton production. According to Mills, Nathanson played a crucial part in the development of the Kiel group and his ideas foreshadow present interests. Yet I - and several of my colleagues in this field - did not know his name or his work. Similarly, the measurements by Penelope Jenkin at Plymouth in the early 1930s established the close relation of photosynthesis to light at different depths in the sea. I doubt if her work is referenced or even remembered now. Recounting such details, Mills makes he point that during their most productive periods these groups were more than an aggregation of talented individuals. They were brought together by the need to collect and interpret diverse kinds of data in ocean physics and chemistry as well as in plankton biology. Mills's analysis indicates that these centres were successful when the collective capabilities and facilities matched the nascent concepts.

The last main actor in Mills's story is the American, Gordon Riley, whose significant work on modelling plankton dynamics was published between 1946 and 1951. Riley worked at Yale University and at the Woods Hole Oceanographic Institution - and later in Nova Scotia. Mills calls him "a loner". He did not establish or participate in a centre in the Kiel or Plymouth tradition. His influence was predominantly through his publications. Mills considers that Riley's work "had surprisingly little impact outside oceanography and is often still unappreci-

\section{ated within it"}

Personally, I place a high value on Riley's work, but Mills's implication is that the social structuring of research groups is a critical element in bringing to fruition new ideas in fields such as oceanography which require diverse technical facilities and close collaborations in field work. The significant impact of a later group established by John Strickland at the Scripps Institution in California shows that this approach of bringing together active researchers in an institutional setting was compatible with the US system and was still appropriate in the period 1960-70 (which is outside the time limits of this book).

In the past decade, new and diverse technologies such as satellites and electronic mail have partially removed the dependence of oceanographers on ships and daily face-to-face interactions. There has also been the emergence of a wider appreciation of global problems encompassing research across the land-sea-air sectors as well as across disciplines. Are the earlier institutional patterns from Kiel, Plymouth and Scripps appropriate to these more recent developments? We are seeing the creation of groups with common scientific interests recruited from several institutions, often in different countries. But the problem of matching scientific concepts to technical abilities still has to work within the limits of human relations. We are in the process of discovering these old constraints in a new context. The rise - and the fall - of previous groups can have a more than historical interest, and Eric Mills's book is relevant to these aspects of carrying out research effectively.

J. H. Steele is at the Woods Hole Oceanographic Institution, Woods Hole, Massachusetts 02543, USA.

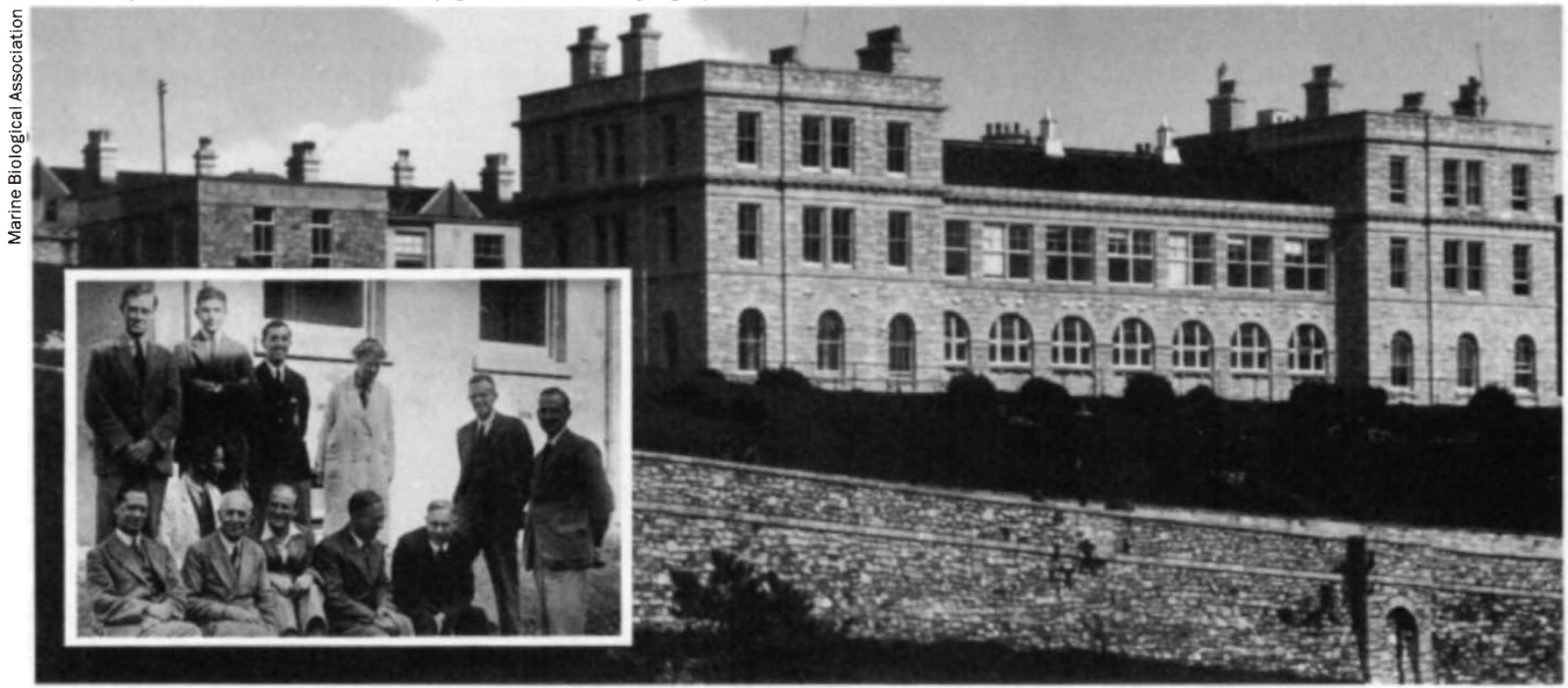

The Marine Biological Association building in the 1930s. Inset, W. H. Harvey (sat on the left) and colleagues, 1933. 